Territorios 32 / Bogotá, 2015, pp. 15-33

ISSN: 0123-8418

ISSNe: 2215-7484

Procesos de ocupación del territorio, historia urbana y patrimonio (I)

\title{
Conservación del patrimonio cultural en el Pueblo Mágico de Tepoztlán, Morelos (2001-2012)
}

Conservation of Cultural Heritage in the Magical Town of Tepoztlan, Morelos (2001-2012)

Conservação do património cultural no Povo Mágico de Tepoztlán, Morelos (2001-2012)

Concepción Alvarado Rosas*

Recibido: 15 de septiembre de 2014

Aceptado: 6 de noviembre de 2014

Doi: dx.doi.org/10.12804/territ32.2015.01

Para citar este artículo:

Alvarado, R. C. (2015). Conservación del patrimonio cultural en el Pueblo Mágico de Tepoztlán, Morelos (2001-2012). Territorios, 32, 15-33. Doi: dx.doi.org/10.12804/territ32.2015.01

\begin{abstract}
* Doctora en Geografía. Universidad Nacional Autónoma de México. Sistema de Estudios de Posgrado e Investigación. Facultad de Arquitectura. Profesora investigadora de tiempo completo, Titular " $A$ ". Universidad Autónoma del Estado de Morelos. Transformación territorial $y$ paisaje sociocultural. Correo electrónico: concepcion. rosas@uaem.mx / connie_ ar2004@yahoo.com.mx.
\end{abstract}


Palabras clave

Patrimonio cultural,

Pueblos Mágicos,

Tepoztlán, México.

Keywords

Cultural heritage, magical towns, Tepoztlan,

Mexico.

Palavras-chave

Património cultural, povos mágicos, Tepoztlán, México.

tersitarias 32

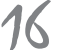

\section{RESUMEN}

La Secretaría de Turismo inició el Programa Pueblos Mágicos en 2001 con el objetivo de dar potencia a la singularidad turística del lugar, creando para ello un imaginario convencional sobre lo que debe ser frecuentado, es decir, establecer un itinerario, por medio de guías prácticas que son reforzadas por las agencias de viajes, folletos, revistas especializadas y páginas web. De este modo, los imaginarios del turismo se construyen a partir de un conjunto de ideas, creencias e incluso prejuicios sobre las actividades y servicios que el turista espera encontrar en el lugar de destino y, en innumerables ocasiones, no coinciden con las prácticas sociales reales de la comunidad. La promoción típica del programa Pueblos Mágicos tiende a fomentar los aspectos más convencionales del patrimonio cultural, lo que deja de lado aspectos locales sustantivos de estos pequeños territorios.

\section{ABSTRACT}

The Ministry of Tourism initiated the magical towns program in 2001, with the goal of augmenting the tourism uniqueness of the place, thus creating a conventional imagination about what should be popular, to establish a pathway through practical guides that are reinforced by travel agents, brochures, magazines and websites. In this way, tourism imaginaries are been constructed from a set of ideas, beliefs and even prejudices about the activities and services that tourists expect to find in the destination and often do not match the actual social practices community. The typical program promoting magical towns tends to encourage the more conventional aspects of cultural heritage, neglecting local substantive aspects of these small territories.

\section{RESUMO}

A Secretaria de Turismo iniciou o Programa Povos Mágicos em 2001, com o objetivo de dar potência à singularidade turística do lugar, criando para isto, um imaginário convencional sobre o que deve ser frequentado, é dizer estabelecer um itinerário através de guias práticas que são reforçadas pelas agências de viagens, folhetos, revistas especializadas e websites. Desta forma, os imaginários do turismo constroem-se a partir de um conjunto de ideias, crenças e inclusive prejuízos sobre as atividades e serviços que o turista espera encontrar no lugar de destino e, em inumeráveis ocasiões, não coincidem com as práticas sociais reais da comunidade. A promoção típica do programa Povos Mágicos tende a fomentar os aspectos mais convencionais do património cultural, deixando de lado aspetos locais substantivos destes pequenos territórios. 


\section{Introducción ${ }^{1}$}

Los espacios se encuentran virtualmente cada vez más cercanos por el desenvolvimiento en las tecnologías de la información y comunicación que, gracias al desarrollo experimentado en la ciencia, hacen evidente el intento por cubrir y acercar al mayor número de individuos a los diferentes territorios, lo que acorta la fricción espacial y permite interactuar de manera simultánea. De esta manera, también se hace evidente el hecho de compartir elementos visibles con los que cuentan los territorios, es decir, se ponen en valor componentes que cumplen un papel fundamental en la comercialización del patrimonio cultural de cada lugar. Los territorios poseedores de un patrimonio cultural, capaz de ser comercializable, y las políticas públicas lograron atrapar esta riqueza para beneficiar a las localidades que ostentan sus tradiciones, costumbres, edificios históricos y paisaje natural, entre otras.

Dentro de esta lógica patrimonialista de ver los bienes materiales e inmateriales, se mantiene este trabajo en el que se analiza la comercialización del patrimonio cultural dentro del programa federal Pueblos Mágicos en Tepoztlán, Morelos (México).

Se ha observado cómo una política federal mexicana pretende utilizar el patrimonio cultural como un vehículo para detonar del desarrollo local por medio de la actividad turística sustentable, que lejos de beneficiar a la población local ha provocado la transformación de su patrimonio y un encarecimiento de la vida en los poblados que cuentan con esta distinción.
El Programa Pueblos Mágicos (PPM) es una iniciativa del gobierno mexicano que está enfocada en un turismo rural en el que se apoyan localidades de hasta 20000 habitantes que posean atractivos culturales susceptibles de ser comercializables por la actividad turística a escala local, regional y nacional y que sean lugares reconocidos por tener un encanto que embelese a todos los visitantes.

\section{Patrimonio cultural comercializable}

El abordaje del patrimonio cultural requiere, previamente, partir de lo que se entiende por cultura. De acuerdo con Granados (2013), esta va más allá de los objetos que la representan, puesto que es más importante comprender el tipo de práctica y los sistemas de significación que utiliza una comunidad para expresar sus ideas y formas de concebir el mundo que lo rodea. Otra visión, que vendría a complementar y a reforzar la anterior, es la de Chihua (2004), quien sostiene que la cultura es un conjunto de herramientas que el actor construye por medio de múltiples estrategias de acción utilizadas para construir el significado de sus experiencias. Por tal motivo, la cultura es un agregado de símbolos, mitos, rituales y visiones del mundo, es decir, interpretan su propia naturaleza y la de todo lo que existe a su alrededor mediante los objetos culturales que sirven para expresar sus ideas, creencias, símbolos expresivos y pautas de valor que son transmitidas, aprendidas y compartidas en la comunidad.
${ }^{1}$ La investigación de la cual se deriva este artículo proviene del proyecto: "Estudios de los imaginarios y rediseno de ciudades turísticas". Dentro del la red temática de colaboración académica denominada "Ciudad Turismose Imaginarios" de la Universidad Autónoma del Estado de Morelos. tersitorios 32

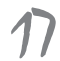


Por su parte, el patrimonio debe ser considerado como una concepción integral, donde lo natural y lo humano se funden para dar origen a un concepto más rico, por la diversidad de elementos que se encuentran en el territorio (Querol \& Martínez, 1996; Criado y González, 1995).

$\mathrm{Al}$ respecto, Llull (2005) y Waisberg (s/f) mencionan que el patrimonio cambia con los periodos históricos, es decir, en la época antigua el patrimonio se consideraba una colección de riquezas y extravagancias que poseían características extraordinarias. Sin embargo, en la época clásica y medieval el patrimonio era vestigio de una civilización considerada superior y se utilizaba como norma y modelo por su valor histórico y estético, así como una herencia invaluable. En el renacimiento y hasta el siglo XVIII, el patrimonio seguía siendo calificado por su valor histórico, más que por su singular belleza.

Para el siglo XIX e inicios del XX, el concepto de patrimonio era más incluyente y no solo se enfocaba en objetos antiguos, es decir, se consideraba el conjunto de expresiones materiales (tangibles) o inmateriales (intangibles) que explicaban históricamente la identidad sociocultural de una nación o un territorio y que, por su condición de símbolos, debían ser conservados y restaurados.

Posteriormente, en la segunda posguerra y hasta la década de los ochenta, el patrimonio se convierte en un elemento esencial para la libertad en la forma de pensar y analizar los objetos que se encontraban interrelacionados, para poder explicar el desarrollo cultural y el mejoramiento de la calidad de vida de las personas. Es decir, nace un interés hacia el patrimonio cultural, donde lo importante es resaltar las características propias de la comunidad para realzar la tradición de los pueblos por medio de sus creencias, costumbres y artesanías, al buscar la conservación, estudio y difusión de los diferentes bienes patrimoniales que contribuirían al progreso ético, cívico y material de la ciudadanía.

En la última década del siglo XX, se produce un hecho fundamental para mercantilizar el patrimonio: el posicionamiento de la actividad turística del ocio. Esta postura estableció masivos patrones de conducta sobre lo que hay que visitar, es decir, la formalización y legitimación convencional que se vale de procedimientos para hacer llegar la oferta a ciertos grupos de población por medio de atractivas revistas de publicidad, agencias de viajes, vistosa folletería, páginas web, etc., que son los instrumentos más utilizados por los promotores para difundir el destino turístico idóneo (Alvarado, 2014).

Actualmente, el patrimonio es considerado una riqueza colectiva de importancia crucial para la democratización de la cultura. En relación con esto, Ballart (1997) menciona que el patrimonio es un distintivo de identidad de un grupo de personas con rasgos propios que la caracterizan e implica un proceso de reconocimiento entre las generaciones presentes y futuras, lo que le da un sentido de pertenencia al grupo como algo exclusivo del territorio. Es importante acotar que el territorio es, entre 
otras cosas, el contenedor de las expresiones culturales que las personas muestran para sentirse identificados con sus raíces y tradiciones.

Subrayar la concepción que Chihua (2004) maneja sobre la identidad es relevante, ya que es un proceso de construcción simbólica de identificación, basado en un marco de referencia como es el territorio, clase, etnicidad, cultura, género edad, etc. Para hacer efectiva esta identidad, Cohen (1985) sostiene que los individuos de una colectividad hacen uso de los símbolos como mecanismos de validez que comparten una historia de tradiciones y valores que los cohesiona en el mantenimiento de la identidad y reproducción de los grupos sociales en el tiempo.

Por su parte, Moreno (2002) menciona que el patrimonio se debe de considerar como fuente de placer, puesto que los pequeños objetos antiguos poseen la virtud de alejarse del mal o fomentar el bien, es decir, tienen la función de ser amuletos del mundo moderno. Del mismo modo, menciona el valor de uso que se le transfiere al bien, significa ingresos para los actores dedicados de manera directa o indirecta a la actividad turística.

Con la imposición del neoliberalismo y la filosofía del libre mercado como norma implacable, el patrimonio, en la mayoría de sus casos, está subordinado a su valorización. La titularidad de los bienes sigue siendo pública, sin embargo, su gestión y ganancias generadas por su uso son predominantemente privadas. Moreno (2002) señala que el papel del patrimonio cultural en la sociedad actual está aún por definirse, puesto que se corre el peligro de envilecerse en beneficio de una demanda sin escrúpulos, perdiendo los valores sociales inherentes. Sin embargo, es inevitable que el libre mercado disponga del uso del patrimonio cultural e intente con mayor eficacia y eficiencia invertir en él.

En la segunda década del siglo XXI, el patrimonio es utilizado por diversos actores, públicos y privados, como un medio para obtener recursos y así poder "beneficiar" a la población. Por ello, en esta comercialización lo relevante es mantener la imagen o cosmética, que sirven como escenario para atrapar al turista. De esta manera, se resalta lo extravagante y la falsa singularidad, lo que conduce inexorablemente a una fase de mercantilización de los bienes.

La Unesco (2011) menciona que el patrimonio cultural no se limita solo a monumentos o colecciones de objetos, sino que el concepto abarca también expresiones vivas heredadas de antepasados y transmitidas a descendientes, tales como tradiciones orales, artes del espectáculo, usos sociales, rituales, actos festivos, conocimientos y practicas relativas a la naturaleza y la cosmovisión, así como saberes y técnicas vinculadas a las artesanías tradicionales. Estos atributos propician, sin lugar a dudas, la cohesión social que se crea, mantiene y transmite de generación en generación.

Garré (2001) menciona que el patrimonio cultural es el conjunto de bienes muebles e inmuebles, materiales e inmateriales, de propiedad particular o de institu- territarias 32

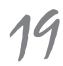


ciones u organismos públicos o semipúblicos que tengan valor excepcional desde el punto de vista de la historia, del arte, de la ciencia y de la cultura, de tal manera, que sean dignos de ser considerados y conservados para la nación.

Como se observa en líneas precedentes, la definición de patrimonio ha evolucionado a un concepto más incluyente, en cuyas transformaciones se encuentran presente dos elementos inseparables: el tiempo y la territorialidad. Por un lado, su carácter de temporalidad pretérita y el valor que posee en sí mismo, por representar en el territorio un hecho que ha marcado pautas a nivel local, regional y nacional, que lo dota de un carácter único y auténtico hacia el interior del lugar, pero también hacia el exterior para ser reconocido por medio de ciertos mecanismos oficiales como es el caso particular del Programa Pueblos Mágicos.

\section{Programa Pueblos Mágicos: comercialización del patrimonio cultural}

Como se había mencionado, el Programa Pueblos Mágicos (PPM) es un proyecto federal de la Secretaría de Turismo (Sectur), que inició en 2001 en la administración del presidente Vicente Fox (2000-2006) y continuo con Felipe Calderón Hinojosa (2006-2012), con esto se resalta que es un programa hasta el momento panista. El programa finalizó en el primer mes de gobierno del presidente priista Enrique Peña territarias 32 20 ro de 2013 y hasta el 26 de septiembre de 2014 el programa se encontraba en revisión y evaluación. A partir del 27 de septiembre inicia su segunda etapa con reglas de operación modificadas y procesos claros para la inclusión y/o permanencia de los pueblos en el programa (Sectur, 2014).

El PPM es un distintivo nacional que busca crear una red o redes alternas a los circuitos turísticos establecidos convencionalmente como una manera de amarrar territorios sueltos que no han sido capaces de consolidar su destino. Por tal motivo, la localidad debe ubicarse a una distancia que no rebase los $200 \mathrm{~km}$, o el equivalente a dos horas de distancia por la vía terrestre, de un destino turístico consolidado, o situarse en una población considerada como mercado emisor (Sectur, 2003). La condición de distancia que impone el programa es relevante, ya que al enfocarse en pequeñas localidades, estas no poseen el equipamiento especializado para soportar una demanda turística sobresaliente.

Para que se inicie el proceso de candidatura, y si es posible la incorporación de la localidad, se requiere del aval oficial de los gobiernos estatal y municipal, mediante un proceso de petición formal, así como de contar con una postulación de la sociedad civil que le dé legitimidad al proceso y lograr así su anexión al programa. El PPM exige, para mantener la vigencia del nombramiento (y el correspondiente recurso federal), contar con planes de desarrollo urbano y ambiental, turístico y comercial, así como de conservar y fomentar el patrimonio inmaterial, por medio de sus fiestas y 
tradiciones representativas (Sectur, 2003). Además de esta normatividad, la localidad debe contar con un Comité de Pueblos Mágicos que este conformado por la población de la comunidad. ${ }^{2}$

El poblado tiene la responsabilidad de producir artesanía local significativa, mantener una cocina tradicional mexicana y contar con servicios turísticos y alojamiento de nivel intermedio. Otro requisito fundamental es la elección de una persona que se encargue de promover y activar las relaciones entre los tres niveles de gobierno: federal, estatal y municipal, es decir, un gestor que sirva como enlace para hacer fluir las demandas entre los tres sectores involucrados en el programa.

El objetivo del programa es fomentar la oferta de la actividad turística, por medio de proyectos detonadores del turismo sustentable que permitan incentivar la inversión y el financiamiento en las localidades, para elevar el nivel de bienestar de los habitantes y mantener e incrementar el empleo. Esta política federal aparentemente ha sido exitosa, puesto que hasta el cierre de la primera etapa del programa (enero 2012) se encuentran 83 pueblos inscritos a lo largo $\mathrm{y}$ ancho del territorio nacional (tabla $1 \mathrm{y}$ figura 1).

Tabla 1. Localidades incluidas en el Programa Pueblos Mágicos, 2001-2012

\begin{tabular}{|c|c|}
\hline Estados & Pueblos Mágicos \\
\hline \multirow{2}{*}{ Aguascalientes } & 1. Real de Asientos \\
\hline & 2. Calvillo \\
\hline Baja California & 3. Tecate \\
\hline \multirow{2}{*}{ Baja California Sur } & 4. Todos Santos \\
\hline & 5. Loreto \\
\hline Campeche & 6. Palizada \\
\hline \multirow{4}{*}{ Coahuila } & 7. Parras de la Fuente \\
\hline & 8. Cuatro Ciénegas \\
\hline & 9. Arteaga \\
\hline & 10. Viesca \\
\hline Colima & 11. Comalá \\
\hline \multirow{3}{*}{ Chiapas } & 12. San Cristóbal de las Casas \\
\hline & 13. Chiapa de Corzo \\
\hline & 14. Comitán de Domínguez \\
\hline \multirow{2}{*}{ Chihuahua } & 15. Creel \\
\hline & 16. Batopilas \\
\hline
\end{tabular}

\begin{tabular}{|c|c|}
\hline \multirow[t]{4}{*}{ Estados } & Pueblos Mágicos \\
\hline & 43. Tacámbaro \\
\hline & 44. Tzintzuntzan \\
\hline & 45. Jiquilpan \\
\hline \multirow{2}{*}{ Morelos } & 46. Tepoztlán \\
\hline & 47. Tlayacapan \\
\hline Nayarit & 48. Jala \\
\hline Nuevo León & 49. Santiago \\
\hline Oaxaca & 50. Capulálpam de Méndez \\
\hline \multirow{5}{*}{ Puebla } & 51. Cuetzalan \\
\hline & 52. Zacatlán \\
\hline & 53. Pahuatlán \\
\hline & 54. Chignahuapan \\
\hline & 55. Cholula \\
\hline \multirow{2}{*}{ Puebla } & 56. Tlatlauquitepec \\
\hline & 57. Xicotepec \\
\hline
\end{tabular}

Conservación del patrimonio cultural en el Pueblo Mágico de Tepoztlán, Morelos (2001-2012)
${ }^{2}$ Para el caso del pueblo mágico de Tepoztlán, Morelos, el comitése denomina Valle Sagrado. El nombre se debe al magnetismo que poseen susmontañasysu territorio, por ser un espacio de culto $y$ adoración a sus símbolos de identidad.

tersitarios 32 21 


\begin{tabular}{|c|c|c|c|}
\hline Estados & Pueblos Mágicos & Estados & Pueblos Mágicos \\
\hline Durango & 17. Mapimí & \multirow{4}{*}{ Querétaro } & 58. Bernal \\
\hline \multirow{5}{*}{ Guanajuato } & 18. Dolores Hidalgo & & 59. Jalpan de Serra \\
\hline & 19. Mineral de Pozos & & 60. Cadereyta de Montes \\
\hline & 20. Jalpa & & 61. Tequisquiapan \\
\hline & 21. Salvatierra & Quintana Roo & 62. Bacalar \\
\hline & 22. Yuriria & \multirow{2}{*}{ San Luis Potosí } & 63. Real de Catorce \\
\hline Guerrero & 23. Taxco & & 64. Xilitla \\
\hline \multirow{4}{*}{ Hidalgo } & 24. Real del Monte & \multirow{3}{*}{ Sinaloa } & 65. Cosalá \\
\hline & 25. Huasca de Ocampo & & 66. El Fuerte \\
\hline & 26. Mineral del Chico & & 67. El Rosario \\
\hline & 27. Huichapan & \multirow{2}{*}{ Sonora } & 68. Álamos \\
\hline \multirow{5}{*}{ Jalisco } & 28. Tepalpa & & 69. Magdalena de Kino \\
\hline & 29. Tequila & Tabasco & 70. Tapijulapa \\
\hline & 30. Mazamitla & \multirow{2}{*}{ Tamaulipas } & 71. Mier \\
\hline & 31. San Sebastián de Oeste & & 72. Tula \\
\hline & 32. Lagos de Moreno & Tlaxcala & 73. Huamantla \\
\hline \multirow{5}{*}{ México } & 33. Tepotzotlán & \multirow{3}{*}{ Veracruz } & 74. Coatepec \\
\hline & 34. Valle de Bravo & & 75. Xico \\
\hline & 35. Malinalco & & 76. Papantla \\
\hline & 36. El Oro & \multirow{2}{*}{ Yucatán } & 77. Izamal \\
\hline & 37. Metepec & & 78. Valladolid \\
\hline \multirow{5}{*}{ Michoacán } & 38. Pátzcuaro & \multirow{5}{*}{ Zacatecas } & 79. Jerez \\
\hline & 39. Tlalpujahua & & 80. Teúl de González Ortega \\
\hline & 40. Cuitzeo & & 81. Sombrerete \\
\hline & 41. Santa Clara del Cobre & & 82. Pinos \\
\hline & 42. Angangueo & & 83. Nochistlán \\
\hline
\end{tabular}

Fuente: elaboración de Fernando López, Rodrigo Flores y Manuel Rueda con base en la información de la Subsecretaría de Operaciones. 


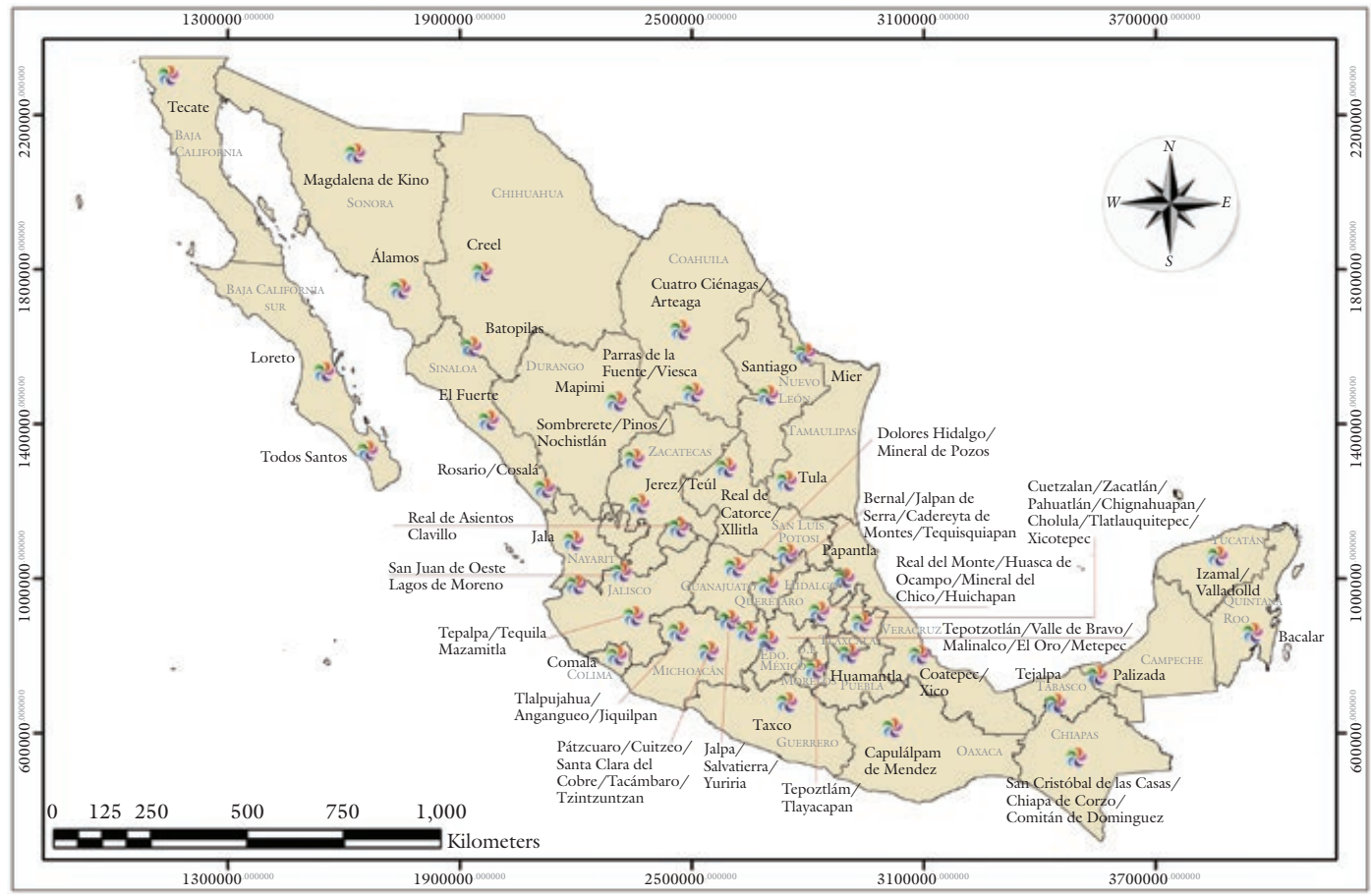

Fuente: Rodrigo Flores R., Manuel Rueda T., Fernando López D., con base en información de la Secretaría de Turismo, 2012.

Como se observa en la Territorialización de los pueblos mágicos del país, el mayor número de localidades se concentra en la región centro y centro sur de Méxi$\mathrm{co}$, por la gran riqueza patrimonial que se encierra en cada uno de estos estados. Lo relevante es conocer si el programa está funcionando como un detonador de desarrollo y crecimiento de las localidades que posee el distintivo o solo es un programa que privilegia a pequeños sectores de la población y deja desprotegidos a los que verdaderamente hacen posible el manteni- miento de las expresiones del patrimonio cultural: la población originaria de las comunidades.

Además del éxito cuantitativo del programa, otro elemento a destacar es el esquema de financiamiento que se mantuvo en ascenso, puesto que inició con una inversión mínima de \$ 4950000 y terminó su primera etapa en diciembre de 2012 con \$ 162818547; es decir, pasó a convertirse en una inversión sostenida durante doce años. En la administración de Vicente Fox, el programa adquirió notable relevancia territarias 32 
al quedar otro panista en la presidencia, Felipe Calderón, donde a partir de 2006, los fondos designados llegaron casi a triplicarse en 2011 donde alcanzo su cúspide en 2012 con \$217692000. Los recursos han representado un aliciente para los gobiernos locales y la iniciativa privada, ya que por medio del distintivo los recursos financieros hacia las localidades pueden realizar una serie de transformaciones urbanas, que sin ellos no hubieran sido posibles.

Por ejemplo, es importante resaltar que los recursos del PPM deben ser transferidos a la población, sin embargo, el caso particular del Pueblo Mágico de Tequila en Jalisco es escandaloso, ya que los recursos se han desviado para los empresarios dedicados a la industria del tequila (Hernández, 2009). Varias de las empresas más importantes en la producción de la bebida espirituosa ya son de capital extranjero.

En Tequila los recursos federales se han enfocado a la cosmética del centro histórico, en la restauración de fachadas y en la rehabilitación de los lavaderos. Estos últimos,

[...] fueron remozados tras la iniciativa y apoyo de las familias Orendáin y Cuervo, así como con recursos públicos, para volverlo otro de los atractivos turísticos de la localidad. Tras el remozamiento, el lugar quedó como nunca antes, ya que durante mucho tiempo los techos para cubrir la hilera de lavaderos eran improvisados, lo mismo que las decenas de tendederos. En cambio, ahora se encuentran techados, pintadas las bardas, adoquinado el piso, y donde alguna vez estuvieron los tendederos se construyeron jardineras así como una amplia cocineta con asadores y banco para preparar alimentos (Hernández, 2009, p. 46).

Otro ejemplo es Valle de Bravo que ingreso al PPM en 2004, los recursos se han focalizado en el mejoramiento en la imagen urbana de la cabecera y localidades más importantes. Por mencionar algunas obras, el mercado municipal, finalización de la Alameda, rehabilitación de malecón, plazas Avándaro y San Antonio, calle Independencia, entre otros (Hoyos, 2008).

Particularmente, el caso del Pueblo Mágico de Tepoztlán Morelos absorbió en toda su vigencia en el programa \$ 44576000. Los recursos han sido utilizados para el mejoramiento del cableado eléctrico subterráneo, pintura para los comercios y casas del primer cuadro del pueblo, donde se muestra una imagen amable hacia el turista, al ofertar un ambiente de modernidad mezclado con lo tradicional.

El remozamiento de la imagen urbana se dirigió prácticamente a la cuadra donde se encuentra el edificio del ex-Convento de Tepoztlán, que integra el museo y la iglesia de Nuestra Señora de la Natividad. En el exconvento se reforzó y rehabilitó la iluminación artística y la ampliación de la red de agua potable (Alvarado, Saldaña, Sorani \& Valenzuela, 2015).

La rehabilitación realizada, a partir de que Tepoztlán ingresó al programa de Pueblos Mágicos, se efectúo hacia los ocho barrios que conforman la cabecera municipal. Según el Informe de Labores de la 
Secretaría de Turismo de 2002, se hicieron trabajos de cableado subterráneo en toda la cabecera municipal. Del mismo modo, se sustituyó el empedrado existente (piedra de río) por empedrado de texcal que es más plano y mejor para caminar. Estas obras cambiaron la imagen urbana, lo que representó quitarle lo tradicional y ponerle una máscara o una escenografía diferente de lo que estaban acostumbrados los pobladores originarios.

En la figura 2 y en tabla 2 se observan las entidades federativas que cuentan con recursos federales. Como se percibe en la figura, tanto Baja California, Durango y Tabasco no han recibido recursos, ya que su inclusión al programa fue en el segundo semestre de 2012 y no tuvieron tiempo para que se les designaran los recursos al suspenderse la primera etapa.
Los estados que recibieron mayores recursos fueron México, Jalisco y Michoacán (tabla 2). Cabe señalar que de los 31 estados donde funciona el PPM, en 9 (29\%) de ellos se concentran 47 localidades, es decir, en pocos estados se localizan $56,6 \%$ de la cartera de pueblos mágicos del país. El estado que cuenta con más localidades en el programa es Michoacán, con 8 pueblos; le sigue, con siete, Puebla; Zacatecas, México, Jalisco y Guanajuato, con cinco en cada uno de ellos; Querétaro, Hidalgo y Coahuila, con cuatro respectivamente.

De 2001 a la tercera parte del 2012 ingresaron solo 49 pueblos y al final del mismo año se integraron otros 34 para sumar 83 localidades con el distintivo de pueblo mágico. En 2013, el Programa Pueblos Mágicos ha entrado en un proceso de evaluación por parte de la Secretaría de

Figura 2. México: Inversión federal del PPM por estados, 2001-2012

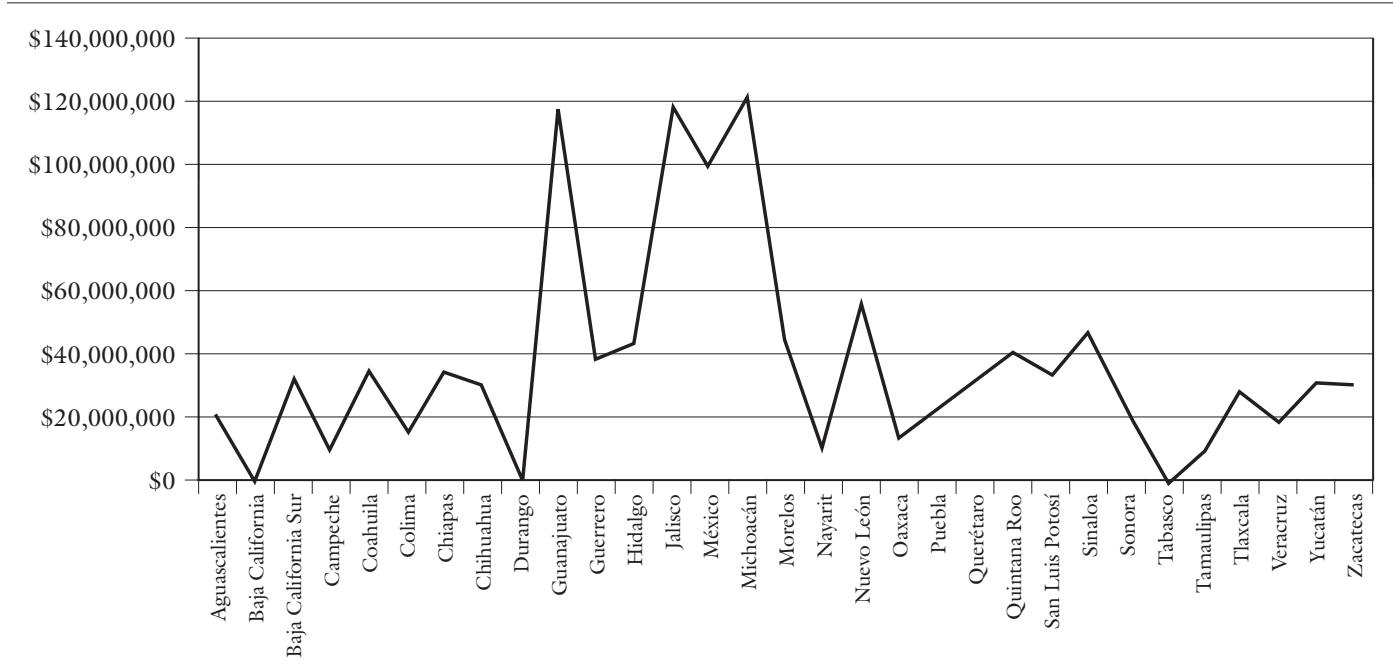

Fuente: Elaboraron Fernando López, Rodrigo Flores, Manuel Rueda con base en la inversión federal, SECTUR. 2012. 
Tabla 2. México: inversión federal de los Pueblos Mágicos

\begin{tabular}{|c|c|c|c|}
\hline Estados & Inversión Federal & Estados & Inversión Federal \\
\hline Aguascalientes & 18750000 & & 0 \\
\hline Baja California & 0 & Nayarit & 9332840 \\
\hline Baja California Sur & 30100000 & Nuevo León & 55350000 \\
\hline Campeche & 9500000 & Oaxaca & 13000000 \\
\hline Coahuila & 33655330 & Puebla & 21951055 \\
\hline Colima & 16166418 & Querétaro & 30600000 \\
\hline Chiapas & 34325,000 & Quintana Roo & 39933333 \\
\hline Chihuahua & 29589000 & San Luis Potosí & 33685000 \\
\hline Durango & 0 & Sinaloa & 46089547 \\
\hline Guanajuato & 116925866 & Sonora & 22100000 \\
\hline Guerrero & 37998000 & Tabasco & 0 \\
\hline Hidalgo & 43864215 & Tamaulipas & 8150000 \\
\hline Jalisco & 118036666 & Tlaxcala & 26890000 \\
\hline México & 99095000 & Veracruz & 18392713 \\
\hline Michoacán & 121523802 & Yucatán & 30158333 \\
\hline Morelos & 44576000 & Zacatecas & 29250000 \\
\hline
\end{tabular}

Fuente: elaboración de Fernando López, Rodrigo Flores, Manuel Rueda con base en la inversión federal, SECTUR. 2012.

Nota: Cabe mencionar que la única entidad federativa de México que no cuenta con el PPM es el Distrito Federal, ya que este posee localidades que rebasan la cantidad de población, además de poseer el programa barrios mágicos promocionado por la Secretaría de Turismo del Distrito Federal.

Turismo, para revisar las reglas de operación, lo que significa que no se va a entregar ningún distintivo más hasta que se emita el resultado oficial de la evaluación.

La actual Secretaria de Turismo, Claudia Ruíz Massieu Salinas, ha mencionado que el programa será revisado, pero no se hará un depurado de la lista que existe hasta el momento, además subrayó que el objetivo de la dependencia es mantener y for- talecer a los integrantes del programa. Del mismo modo, mencionó que todo lo que va del año 2013 la Secretaría de Turismo se ha dedicado a realizar un estudio de evaluación (Flores, 2013). Posiblemente, como resultado de la valoración, se buscarán mecanismos más rigurosos. Cabe mencionar que la política regional de turismo ha llamado la atención en otros países de América Latina (El Salvador, Ecuador, Perú, Colombia y 
Chile), ya que han solicitado asesoría a la Sectur por el éxito detonador en el desarrollo de las localidades (De la Rosa, 2012).

Como se mencionó, de los estados donde se encuentra presente el PPM se seleccionó Tepoztlán como una de las dos localidades con que cuenta Morelos por ser un pueblo que se ha consolidado en trece años, a pesar de salida y reingreso al programa, como un destino turístico reconocido.

\section{Tepoztlán: elementos contenedores del nombramiento Pueblo Mágico}

En 2002, Tepoztlán obtuvo la categoría de Pueblo Mágico y en octubre de 2009 le retiraron el distintivo para volver a recuperarlo en abril de 2010. Cabe destacar que cualquier localidad que pierda el distintivo, solo lo puede volver a obtener una sola vez. El reconocimiento que posee Tepoztlán como Pueblo Mágico se lo debe principalmente por contar con edificios de valor arquitectónico, casas de adobe, topografía, fiestas, artesanías y gastronomía.

El municipio de Tepoztlán está conformado por siete pueblos: San Andrés de la Cal, Santo Domingo Ocotitlán, Santiago Tepetlapa, Amatlán de Quetzalcoatl, San Juan Tlacotenco, Santa Catarina y Tepoztlán y cada uno de los pueblos se encuentra dividido en barrios.

\subsection{Edificio arquitectónico}

El edificio arquitectónico más importante en Tepoztlán es el ex-Convento, junto a él se localiza la iglesia de la Natividad, construida alrededor de 1570 (Tostado, 1995). El exconvento fue nombrado Patrimonio Mundial de la Humanidad en 1994. El municipio cuenta, además, con la Zona Arqueológica y el Parque Nacional El Tepozteco, que desde 1937 el presidente Lázaro Cárdenas lo decreto como parque.

El pueblo de Tepoztlán posee ocho barrios y en cada uno de ellos se localiza una capilla construida en el siglo XVII, en cuyos espacios se observa la fusión de tradiciones prehispánicas y novohispanas en los templos. Para ilustrar mejor, en el barrio de San Miguel se observa en la entrada de la capilla la imagen del arcángel San Miguel y la lagartija, como animal totémico, símbolo de arraigo entre los nativos del barrio. En entrevistas realizadas en el trabajo de campo, los residentes mencionaban que en épocas pasadas se encontraban lagartijas por todas partes.

Como lo mencionaba Dubernard (1983), cada barrio tiene su imagen católica y su animal totémico. San Pedro es el barrio del tlacuache, Los Reyes es el de los gusanos de maguey, San Sebastián del alacrán, Santa Cruz del cacomixtle, La Santísima de la hormiga, San Miguel de la lagartija, Santo Domingo del sapo, San José de la hoja de elote (figura 3 ).

Si bien, a los barrios se les designaba una imagen católica y un animal, también cada barrio tenía una característica que los distinguía entre sus vecinos, esto era la actividad a la cual se dedicaban los pobladores, por ejemplo, en Santa Cruz se dedican a la elaboración de cohetes, en San Sebastián territarias 32 


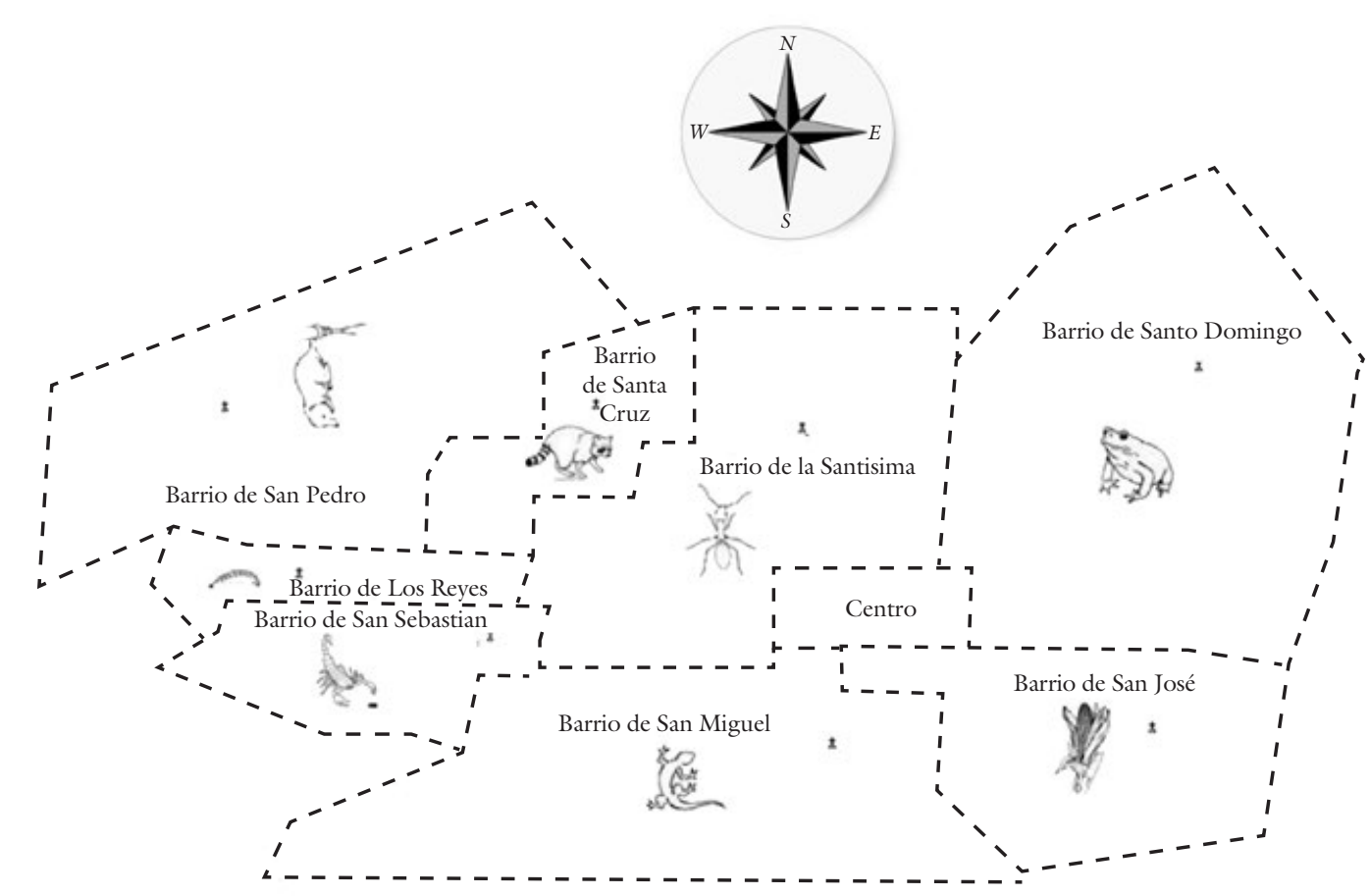

Fuente: elaboración de Rodrigo Flores R., Manuel Rueda T., Fernando López D., con base en Dubernard, 1983.

confeccionan reatas, en Santo Domingo se dedican a la teja, en San Miguel son agricultores o jornaleros, en Los Reyes venden carbón y en San Pedro se dedican a la siembra y a vender carbón y leña (Chihua, 2004).

\subsection{Casas de adobe}

Otro elemento importante que contribuyó para el nombramiento de Pueblo Mágico

\section{territarias 32} 28 censo realizado en el trabajo de campo de marzo a junio de 2014 (Nava, 2014), en los ocho barrios del pueblo de Tepoztlán se contabilizaron 125 viviendas de adobe, de las cuales algunas se encuentran deshabitadas o están siendo remodeladas en sus fachadas. Los habitantes del poblado mencionan que el cambio en sus casas de adobe por materiales convencionales se debe a que tienen recursos económicos que les han permitido tener casas modernas, es común encontrar esta práctica en la población originaria, sin pensar que es una 
riqueza patrimonial que le está confiriendo una personalidad y carácter particular a Tepoztlán.

Es común en las calles principales del pueblo de Tepoztlán encontrar algunas fachadas de las casas de adobe recubiertas con cemento y pintadas de colores convencionales. Esta imagen cosmética provoca entre los residentes originarios no identificarse con sus símbolos de identidad, puesto que la transformación ha funcionado como un elemento de rechazo. Sin embargo, para los visitantes ha sido un atractivo para establecer itinerarios convencionales de recorridos turísticos.

\subsection{Topografía}

Su topografía está conformada por un conjunto de elevaciones que tienen nombres y cada habitante los identifica. La composición de todas estas elevaciones se inicia en el cerro del Ocelote (Ocelotepetl), cerro del hombre (Tlacatepetl), que algunos habitantes mencionan que tiene la forma de un rostro varonil, el cerro que alumbra (Tlahuiltepetl), cerro del aire (Ehecatepetl), el cerro de las gotas de agua (Manilaltepetl), el cerro del vigilante nocturno (Yohualtecatl), cerro del otate (Otlatepetl), cerro de la manita (Cematzin), algunos pobladores lo conocen como la pata de buey, cerro de la esmeralda o del tesoro (Chalchihuitepetl) y el cerro de la miel (Cuahnectepetl) (Dubernard, 1983). En esta última elevación se muestra una parte significativa de la expansión urbana presentada a finales de la década del sesenta del siglo XX.
Todas las elevaciones mencionadas son un orgullo para los oriundos de Tepoztlán, puesto que en su imaginario colectivo consideran la composición orográfica como un regalo divino que les permite sentirse protegidos, cuidados y abrazados por las montañas.

En el cerro de Thahuiltepetl se encuentra una pequeña meseta donde se localiza la pirámide dedicada al dios Tepozteco, construida por los tepoztecos entre 1150 y 1350 d.C. La pirámide se levantó en nombre de Ometochtli, dios del pulque relacionado con la fertilidad y las buenas cosechas. Este espacio ha sido un santuario importante para las manifestaciones culturales, puesto que sus pobladores realizan cada año el reto al Tepozteco, donde llevan ofrendas y hacen rituales en honor al rey tepozteco para que el pueblo tenga un año de prosperidad y buenas cosechas. Del mismo modo, en sus cerros se encuentran cascadas y pinturas rupestres localizadas en las cuevas de las faldas de la serranía.

En el excepcional paisaje orográfico se encuentran caprichosas formas rocosas que le proveen un aspecto único de su belleza escénica y, sobre todo, funciona como un elemento de identificación a su territorio, puesto que son espacios donde la población realiza sus festividades.

\subsection{Las fiestas}

Una de las fiestas más importantes en Tepoztlán es el reto al tepozteco, consiste en hacer una ofrenda en la pirámide del Tepozteco, el siete de septiembre, en la territarias 32 
víspera de las fiestas de la Virgen de la Natividad. La población y el presidente municipal suben al cerro del Tepozteco, llevan una ofrenda que es colocada en la pirámide. Posteriormente, el ocho de septiembre se escenifica una representación teatral, donde Tepoztecatl, conocido como el dios Tepozteco, fue convertido a la nueva religión católica desde el momento que fue bautizado por Fray Domingo de la Anunciación. Tepoztecatl se enfrenta a los reyes de Cuaunáhuac, Tlayacapan y Yautepec por rechazar al nuevo dios, pero el rey recién convertido a la religión católica los convence para dejar a sus dioses.

Como resultado de la práctica prehispánica y novohispana, algunos de los atractivos relevantes son las tradiciones que se desprenden del sincretismo que gurda Tepoztlán, en cuyos rinconcitos ofrecen fiestas patronales con ferias y fuegos artificiales que deleitan a los visitantes nacionales y extranjeros. Para tener una idea de relevancia del jolgorio tepozteco, todos los días del año tienen una fiesta dedicada a una imagen católica o a un ritual prehispánico, es decir, se escuchan cohetes y música prehispánica (teponaxtle) o de banda para deleitar a los feligreses que asisten a las iglesias a festejar el santo patrono o a la plaza principal a observar las representaciones teatrales o simplemente a ver bailar a sus chinelos.

No podía dejarse de lado el portal de semillas, que a partir del último cuarto del siglo XX ha tomado una relevancia fundamental en Tepoztlán. El ocho de septiembre se pone este portal, que mide 7 x 11 $\mathrm{m}$, en la entrada principal de la iglesia de la
Natividad. El motivo de la portada está relacionada con los ritos mexicanos (Saldaña \& Alvarado, 2014).

\subsection{Artesanías}

Un aspecto muy relacionado con las fiestas del pueblo son las bellas artesanías. Estos ejemplos bastan para ilustrar lo dicho con la ingeniosa elaboración de la corteza de árbol de amate y pochote. Las artesanías de las casitas de pochote datan de la década del cuarenta del siglo XX, cuando una persona llegó del estado de México a cuidar la pirámide del tepozteco, su creatividad llevó a esta persona a elaborar con la corteza de árbol casitas que aparentaban estar enclavadas en la serranía del Tepozteco (Bahena \& Gallardo, 2011). Del mismo modo, se encuentran utensilios de madera para la cocina, alebrijes para adornar y proteger las casas, aretes y pendientes de semillas, etc. Cabe mencionar que los pobladores han desarrollado la habilidad de crear aretes, pulseras y otros pendientes de semillas, resultado de la tradición reciente del portal de semillas que ponen los residentes del pueblo en la entrada principal de la iglesia de la Natividad.

\subsection{Gastronomía}

Como resultado de una mezcla de diferentes culturas, tanto la prehispánica como la española, y en menor medida la africana, aportaron alimentos y condimentos que se convirtieron en un distintivo en diferentes lugares del territorio nacional. Como es el 
caso de Tepoztlán, con la preparación del mole verde de pepita, los tlacoyos, los tamales nejos, los texcales y los itacates (Ortíz, Ramírez, Lino, Mondragón, Ballastra \& Melquiades, 2000).

Los atributos mencionados han sido elementos que le otorgaron el reconocimiento a Tepoztlán en 2002. La localidad fue una de las primeras en conformar la lista de los Pueblos Mágicos de México. Desafortunadamente, le retiraron el distintivo en 2009 por la excesiva venta de productos chinos, invasión de puestos semifijos en la vía pública, abundancia de anuncios publicitarios que dañaban la imagen urbana y proliferación de establecimientos con venta de bebidas alcohólicas.

Para poder corregir estos problemas, el gobierno municipal implementó diferentes medidas, como un mayor control a las licencias para venta de bebidas alcohólicas y otros giros relacionados con el comercio. Fomentaron entre la población la venta y elaboración de sus sus artesanías y reordenaron el comercio semifijo en áreas destinadas solo para este fin.

Cabe destacar que entre las festividades más importantes que posee el pueblo de Tepoztlán, por la cantidad de visitantes que recibe, es el carnaval. Las autoridades, para controlar la venta y distribución de bebidas embriagantes, así como restringir el deambular de las personas con bebidas, ha designado espacios en los que se localizan este tipo de comercios, y las autoridades no dejan salir a personas con bebidas a la vía pública.
Estas medidas han venido a cumplir con los lineamientos del PPM y, lo más importante, un sector de la población del pueblo de Tepoztlán ha elogiado las acciones del presidente municipal, puesto que en las festividades más importantes se han corregido problemas que afectaban a los habitantes.

\section{Conclusiones}

La distinción de Pueblo Mágico que poseen ciertos pueblos de la geografía nacional debe ser un apoyo real para detonar el desarrollo y crecimiento económico de las localidades enfocadas al turismo sustentable y no ser solo un beneficio para ciertos sectores empresariales.

Si el patrimonio cultural es de todos y, particularmente, de los residentes poseedores de ese legado, se espera que la comercialización de este llegue de manera directa a los que procuran la manifestación y expresión de los símbolos de identidad que le dan un carácter y personalidad única.

$\mathrm{Si}$ este programa federal busca detonar el turismo sustentable de las pequeñas localidades y representar un ingreso extra a los habitantes, paradójicamente no están siendo beneficiados por el uso y manejo de su patrimonio. En entrevistas realizadas a la población originaria del pueblo de Tepoztlán mencionaban que, a partir del nombramiento, sus ventas se han desplomado y que cada día es más complicado dedicarse solo a la elaboración de artesanías. Para complementar el ingreso familiar, miembros de la población trabajan como territarias 32 
meseros, recepcionistas, camareras o cocineras para poder complementar el salario y poder mantener a su familia.

Si actualmente el PPM se encuentra en revisión, se deben atender las necesidades reales de la población de los pueblos mágicos para que realmente sean beneficiados de la derrama económica que realizan los turistas en estas pequeñas localidades.

\section{Referencias}

Alvarado, C. (2014). El Programa Pueblos Mágicos: entre la realidad y la fantasía. En A. Valenzuela, C. Alvarado \& M. C. Saldaña (Coord.), Imaginarios del paisaje y el turismo entre tradición $y$ distintivos oficiales. México, Distrito Federal: Juan Pablo Editor y Universidad Autónoma del Estado de Morelos. Alvarado, C., Saldaña, C., Sorani, V., \& Valenzuela, A. (2015). Un regalo de Dios... Tepoztlán. En C. Alvarado, A. Babini, M. Guillén, S. Rojo \& E. Méndez (Coords.), Lugares de encuentro. Una visita a pueblos mexicanos. Hermosillo: El Colegio de Sonora. (En prensa).

Bahena, M., \& Gallardo, C. (2011). Morelos. Estudios de las entidades donde vivo. México: Secretaría de Educación Pública.

Ballart, J. (1997). El Patrimonio Histórico y Arqueológico: valor y uso. Madrid: Ariel.

Chihua, A. (2004). El tepozteco, símbolo de identidad colectiva. Argumentos, 46-47, 177-196.

Cohen, A. (1985). The symbolic construction of community. Londres: Tavistock.
Dubernard, J. (1983). Apuntes para la historia de Tepoztlán. México: Talleres Impresores de Morelos S.A.

Flores, F. 2013. Sectur somete a revisión a los Pueblos Mágicos. El Financiero. Recuperado de http://www.elfinanciero. com.mx/secciones/culturaentretenimiento/28210-sectur-descarta-depuracion-de-la-lista-de-pueblos-magicos. html.

Garré, F. (2001), Patrimonio arquitectónico urbano, preservación y rescate: bases conceptuales e instrumentos de salvaguarda. Conserva. Revista del Centro Nacional de Conservación y Restauración, 5, 5-22.

Granados, L. (2013). Cochambre, vida urbana y 'afresamiento'. Reflexiones acerca del rescate de algunos centros históricos y su relación con la noción de patrimonio cultural. Patrimonio cultural y turismo. Cuadernos, 19, 113-118. Recuperado de http://arpa.ucv.cl/archivum6/patrimonio/1.\%20BREVES\%20 REFERENCIAS\%20AL\%20CONCEPTO\%20DE\%20PATRIMONIO... M. WAISBERG.pdf.

Hernández,J. (2009). Tequila: Centro Mágico, Pueblo Tradicional. ¿Patrimonialización o privatización? Andamios, 6(12), 41-67.

Hoyos, G., Hernández, O. (2008). Localidades con recursos turísticos y el Programa Pueblos Mágicos en medio del proceso de la nueva ruralidad. Los casos de Tepotzotlán y Valle de Bravo en el estado de México. Quivera, 10(2), 111-130.

\section{territarios 32}


Llull, J. (2005). Evolución del concepto y de la significación social del patrimonio cultural. Arte, Individuo y Sociedad, 17, 175-204. Recuperado de http://revistas.ucm.es/index.php/ARIS/article/ view/ARIS0505110177A/5813

Lewis, O. (1976). Tepoztlán un pueblo de México. México: Editorial Joaquín Mortíz.

Moreno, M. (2002). Patrimonio cultural. Puesta en valor y uso. Una reflexión. Vector plus: miscelánea científico-cultural, 7, 41-49.

Ortiz, T., Ramírez, N., Lino, C., Mondragón, B., Ballastra, P., \& Melquiades, $S$. (2000). Cocina indigena morelense. De fogón en fogón. México: CONACULTA. Culturas Populares e Indígenas.

Querol, M., \& Martínez, B. (1996). La gestión del Patrimonio Arqueológico en España. Madrid: Alianza.

Rosa, A. de la. (2012). Replicaran el programa pueblos mágicos en el extranjero. El Economista. Recuperado de http://eleconomista.com.mx/industrias/2012/09/16/replicaran-programa-pueblos-magicos-extranjero

Saldaña, F. C., \& Alvarado, C. (2014). Los imaginarios en Tepoztlán, Morelos. Inventio, 20,11-18.
Secretaría de Turismo. (2003). Pueblos Mágicos. Reglas de operación. México: Sectur.

Secretaría de Turismo. (2012). Inversión federal en el Programa Pueblos Mágicos, 2011-2012. México: Secretaría de Turismo.

Secretaría de Turismo, Consejo Nacional de Ciencia y Tecnología y Centro de Estudios Superior en Turismo. (2014). Evaluación de desempeño de los destinos turísticos en el marco de los Convenios de Coordinación en materia de Reasignación de Recursos (CCRR). Análisis del desempeño turístico local. Modelo de satisfacción de los turistas.

Tostado, M. (1995). Mini guía del ex convento de la Natividad Tepoztlán. Morelos: Instituto Nacional de Antropología e Historia.

Unesco (2011). ¿Qué es el patrimonio cultural inmaterial? Recuperado de http:// www.unesco.org/culture/ich/doc/ src/01851-ES.pdf

Waisberg I. (s/f). Breves referencias al concepto de patrimonio arquitectónico en las últimas décadas. Archivum, V(6), 256-265. territarias 32

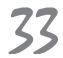


